\title{
Evolução estratigráfica da Sequência Neocarbonífera-Eotriássica da Bacia do Parnaíba, Brasil
}

\author{
Stratigraphic evolution of the Upper
}

Carboniferous-Lower Triassic Sequence, Parnaíba Basin, Brazil

\author{
Éverton Nóbrega Barbosa ${ }^{1 *}$, Valéria Centurion Córdoba ${ }^{2}$, Debora do Carmo Sousa ${ }^{3}$
}

RESUMO: A Sequência Neocarbonífera-Eotriássica corresponde ao terceiro grande ciclo sedimentar da Bacia do Parnaíba e concerne litoestratigraficamente ao Grupo Balsas. Essa sequência é descrita como um conjunto de rochas cujos sedimentos foram depositados em um ambiente complexo, clástico/evaporítico de mar raso, gradando para um ambiente lacustre/ desértico. O principal objetivo deste trabalho foi realizar uma análise estratigráfica da Sequência Neocarbonífera-Eotriássica, visando uma melhor compreensão da sua evoluçáo. Tal análise teve por base dados de poços e algumas seçōes sísmicas. Para o intervalo estratigráfico em questáo foram identificadas três sequências deposicionais. A Sequência 1 corresponde a rochas que foram depositadas inicialmente a partir de um sistema fluvial, que passa para um sistema marinho raso implantado durante uma fase transgressiva e, posteriormente, evolui para um sistema deltaico. A Sequência 2 corresponde a rochas que foram depositadas a partir de um sistema deposicional lacustre/desértico, representando uma fase regressiva importante que culmina com a implantaçâo de um sistema desértico, o qual corresponde à Sequência 3. Na análise sismoestratigráfica foi possível reconhecer as superficies cronoestratigráficas e os tratos de sistemas identificadas em poços e analisar a sua expressão lateral. De modo geral, as sismofácies reconhecidas nas seçōes sísmicas apresentam-se com configuraçôes paralelas a subparalelas, com grande continuidade lateral, sugerindo uma homogeneidade nas taxas de sedimentaçấo durante a deposição dessas sequências, nesse setor da bacia. PALAVRAS-CHAVE: Estratigrafia de Sequências; Sismoestratigrafia; Sinéclise Paleozoica.
ABSTRACT: The Upper Carboniferous-Lower Triassic Sequence represents the third major sedimentary cycle of the Parnaiba Basin in northeastern Brazil and corresponds to the Balsas Group. The sequence is composed by a thick pack of siliciclastic rocks whose sediments were deposited under complex conditions, varying from clasticlevaporitic shallow marine to lacustrine and desert environment. Aiming to clarify the sedimentary sequence evolution, this work conducted a stratigraphic analysis of the Upper Carboniferous-Lower Triassic sediments. Modern and classic concepts of sequence stratigraphy were applied on a database of wells and seismic sessions. We identified three main depositional sequences. Sequence 1 corresponds to rocks initially deposited by a fluvial system which evolved to shallow marine conditions related to a transgressive stage, later evolving to a deltaic system. Sequence 2 corresponds to sediments deposited under lacustrinelarid conditions, during an important regressive stage, that evolved to a dominantly desert environment recorded in Sequence 3. Seismic stratigraphic analyses allow to infer key stratigraphic surfaces, and three main sequences. Seismic facies related with such sequences are dominantly parallel and sub-parallel, with good lateral continuity, suggesting that the sedimentary rates were homogenous along the interval analyzed in this sector of Parnaiba Basin.

KEYWORDS: Sequence Stratigraphy; Seismic Stratigraphy; Paleozoic Syneclise.

\footnotetext{
${ }^{1}$ Programa de Pós-Graduação em Geodinâmica e Geofísica, Universidade Federal do Rio Grande do Norte - PPGG/UFRN, Natal (RN), Brasil. E-mail: nbeverton@gmail.com ${ }^{2}$ Programa de Pós-Graduação em Geodinâmica e Geofísica - PPGG; Departamento de Geologia, Universidade Federal do Rio Grande do Norte - UFRN, Natal (RN) Brasil. E-mail:valeria.geo@ufrnet.com

${ }^{3}$ Departamento de Geologia, Universidade Federal do Rio Grande do Norte - UFRN, Natal (RN), Brasil. E-mail: debora@geologia.ufrn.br

*Autor correspondente.

Manuscrito ID: 20150021. Recebido em: 07/08/2015. Aprovado em: 19/05/2016.
} 


\section{INTRODUÇÃO}

A Bacia do Parnaíba tem sido alvo de vários estudos estratigráficos, em sua maioria com abordagem litoestratigráfica. O crescente interesse das companhias de petróleo nesta bacia vem impulsionando a aplicação de abordagens estratigráficas modernas baseadas nos conceitos da Estratigrafia de Sequências. Além disso, uma integração mais eficaz entre os dados de subsuperfície e as ferramentas de análise estratigráfica tornou as interpretaçóes mais precisas.

Este trabalho se propôs a analisar a Sequência Neocarbonífera-Eotriássica da Bacia do Parnaíba, visando elaborar uma proposta de evolução estratigráfica, com base nos conceitos da Estratigrafia de Sequências. Trabalhos anteriores com ênfase na caracterização de fácies, na interpretação de sistemas deposicionais ou ainda na definição de unidades estratigráficas genéticas nessa sequência contribuíram para a análise em questão. Destacam-se os trabalhos de Melo \& Prade (1968), Lima \& Leite (1978), Faria Junior. (1979), Oliveira (1982), Góes \& Feijó (1994), Milani \& Thomaz Filho (2000); Ribeiro (2000), Dino et al. (2002), Vaz et al. (2007), Andrade (2012), Abrantes Júnior (2013) e Medeiros (2013).

\section{MATERIAIS E MÉTODOS}

Métodos de análise estratigráfica $1 \mathrm{D}$ e $2 \mathrm{D}$ foram utilizados para obtenção dos resultados descritos neste trabalho. No total, foram analisados seis perfis de poços e quatro seçôes sísmicas que abrangem completamente o intervalo estudado. Esses dados foram cedidos pelo Projeto de Pesquisa "Geologia e Sistemas Petrolíferos da Bacia Intracratônica do Parnaíba, Nordeste do Brasil” (BPAR), desenvolvido no âmbito da Universidade Federal do Rio Grande do Norte (UFRN)/Fundação Norte-Rio-Grandense de Pesquisa de Cultura (Funpec)/Chevron. Os poços e as linhas sísmicas encontram-se inseridos na porção centro-norte da Bacia do Parnaíba (Estado do Maranhão) e ocupam áreas distintas (porçôes oeste, central e leste), permitindo boa compreensão das variaçóes faciológicas (Fig. 1).

Existem vários modelos de sequência em uso, criados por diferentes autores para adequar o modelo clássico de sequências, elaborado por Sloss (1963), a condiçóes específicas (Galloway 1989; Van Wagoner et al. 1988; Embry \& Johannessen 1992; Hunt \& Tucker 1992; Catuneanu 2006). A elaboração deste trabalho contou com a aplicação do modelo estratigráfico apresentado por Holz (2012), em que quatro tratos de sistemas são descritos: o Trato de Sistemas de Nível de Mar Baixo (TSNB); o Trato de Sistemas Transgressivo (TST); o Trato de Sistemas de Nível de Mar Alto (TSNA); e o Trato de Sistemas de Regressão Forçada
(TSRF). De um modo geral, esse modelo se assemelha ao clássico tripartite proposto por Van Wagoner et al. (1988). A escolha do modelo de Holz (2012) se revelou aplicável de forma satisfatória ao intervalo cronoestratigráfico analisado.

A etapa de análise $1 \mathrm{D}$ consistiu na avaliação e interpretação dos dados de poços e seguiu os seguintes passos:

1. elaboração de uma seção colunar para cada poço, utilizando as informaçóes dos perfis de raios gama e litológico;

2. reconhecimento das litofácies e inferência dos sistemas deposicionais;

3. delimitação dos ciclos e dos conjuntos de ciclos;

4. identificação de superfícies cronoestratigráficas e unidades genéticas a partir do reconhecimento de mudanças nos padrôes de empilhamento dos conjuntos de ciclos;

5. confecção de histogramas contendo informaçóes da variação proporcional das fácies, as quais foram quantificadas, relativamente, por ciclo;

6. elaboração de diagramas 1D para cada poço.

A análise $2 \mathrm{D}$, realizada em seguida, teve como objetivo principal o rastreamento das superfícies-chave e unidades genéticas que foram reconhecidas durante a análise 1D. A Fig. 1 ilustra a localização dos poços analisados, da seção de correlação elaborada e das seçóes sísmicas estudadas. A seção sísmica A é a única que será apresentada neste trabalho, já que as outras três se assemelham a esta e a seção A é a que apresenta a melhor continuidade dos refletores.

\section{CONTEXTO GEOLÓGICO}

A Bacia do Parnaíba está localizada na porção noroeste do Nordeste brasileiro e em uma pequena porção do Norte do país (Fig. 1), ocupando uma área de aproximadamente $600.000 \mathrm{~km}^{2}$ (Vaz et al. 2007). Trata-se de uma bacia circular do tipo sag, com $3.500 \mathrm{~m}$ de espessura em seu depocentro (Milani \& Thomaz Filho 2000).

A sucessão de rochas sedimentares que compóe a Bacia do Parnaíba pode ser compartimentada em cinco grandes sequências deposicionais, das quais três iniciaram o processo de deposiçáo no Paleozoico (Siluriana, MesodevonianaEocarbonífera e Neocarbonífera-Eotriássica), e duas foram depositadas no Mesozoico (Jurássica e Cretácea) (Góes \& Feijó 1994). Essas sequências são delimitadas por discordâncias que representam importantes hiatos deposicionais e se estendem por toda a bacia ou abrangem extensas regióes (Vaz et al., 2007).

\section{A Sequência Neocarbonífera-Eotriássica}

A Sequência Neocarbonífera-Eotriássica da Bacia do Parnaíba foi designada por Góes \& Feijó (1994) como 
correspondente ao terceiro grande ciclo sedimentar, estando sobreposta discordantemente à Sequência MesodevonianaEocarbonífera. Essa sequência corresponde ao Grupo Balsas e representa uma sucessão de rochas depositadas em um complexo ambiente clástico/evaporítico de mar raso, gradando para um ambiente continental dominado por sistemas lacustre e desértico (Vaz et al. 2007). Litoestratigraficamente, o Grupo Balsas é composto por quatro formaçóes: Piauí, Pedra de Fogo, Motuca e Sambaíba. A Fig. 2 mostra a carta estratigráfica da Bacia do Parnaíba proposta por Vaz et al. (2007).
As rochas que compóem a Formação Piauí representam o início da deposiçáo sedimentar do Grupo Balsas ainda durante o Pensylvaniano (Fig. 2) (Vaz et al. 2007). Lima \& Leite (1978) interpretaram que tais rochas foram depositadas a partir de um sistema fluvial com contribuição eólica e breves incursões marinhas, sob condiçôes de aridez climática. Essa formação foi descrita por Ribeiro (2000) como sendo constituída principalmente por rochas areníticas e, subordinadamente, por rochas conglomeráticas e siltíticas. Essa unidade possui contato erosivo com a formação subjacente (Formação Poti).

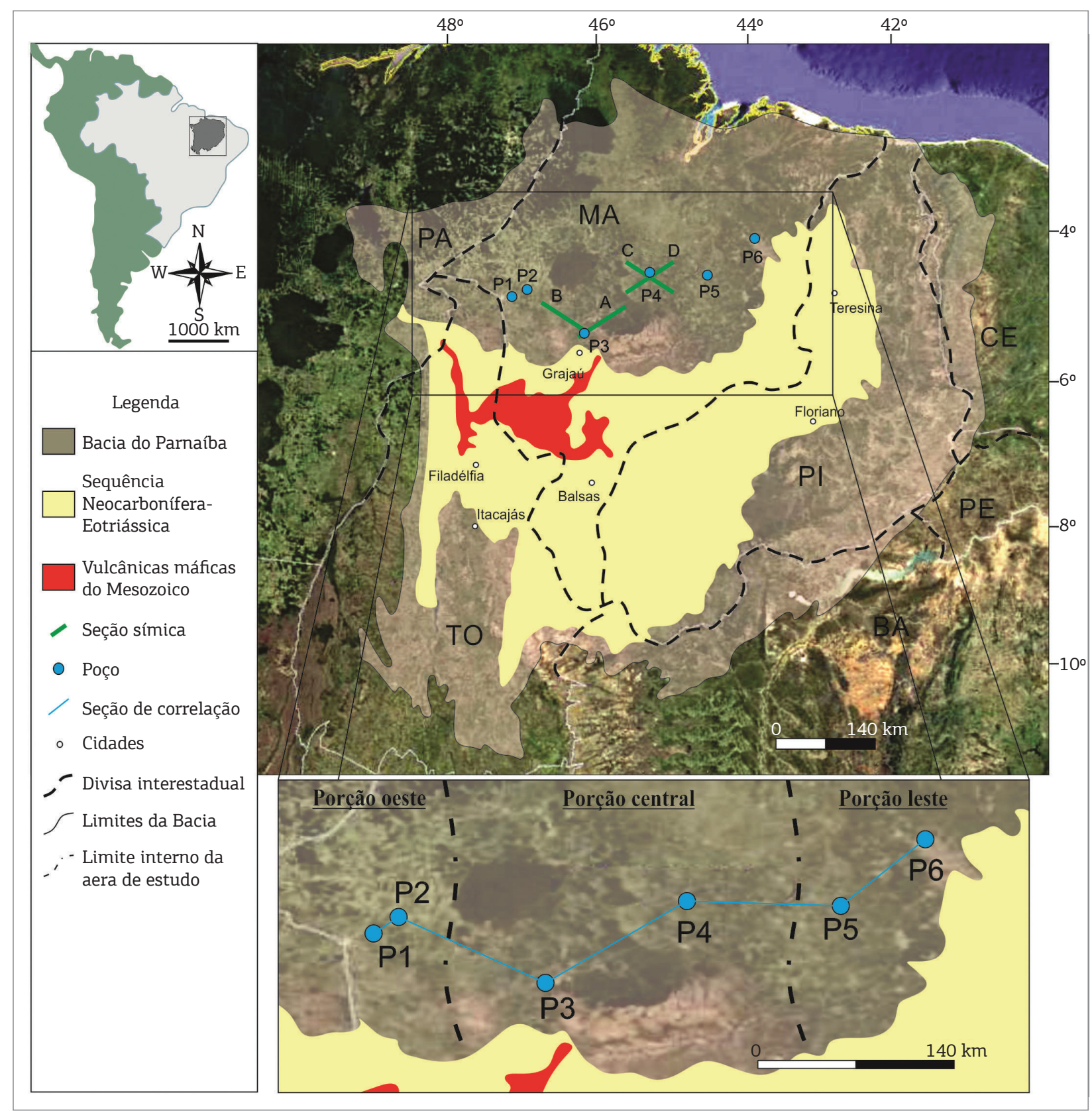

Figura 1. Localização e limites da Bacia do Parnaíba com ênfase na distribuição espacial da Sequência Neocarbonífera-Eotriássica aflorante e na localização dos poços, das seções sísmicas analisadas e da seção de correlação confeccionada. Modificado de Santos \& Carvalho (2004). 
As rochas que constituem a Formação Pedra de Fogo foram geradas a partir de sedimentos depositados durante quase todo o Permiano, sendo representadas por uma considerável diversidade litológica, que varia desde silexitos, calcários (eventualmente com estromatólitos), arenitos, folhelhos, siltitos, evaporitos (anidrita) até dolomitos (Fig. 2) (Vaz et al. 2007). Com base em dados palinológicos, Dino et al. (2002) interpretaram que tais rochas foram depositadas em um ambiente marinho raso a costeiro, em clima árido a semiárido quente. No entanto, trabalhos mais recentes, como o de Andrade (2012), definem a parte superior da Formação Pedra de Fogo como uma sucessão siliciclástica, com subordinadas ocorrências carbonáticas/evaporíticas, relacionada a um sistema lacustre de clima árido com contribuiçôes de rios efêmeros e cercado por campos de dunas e planícies de sabkha continental. Medeiros (2013) também afirma que, durante o final do Permiano, um sistema lagunar de clima árido se implantou na Bacia do Parnaíba, em que planícies de sabkha eram formadas nas porçóes marginais. Araújo (2015) interpretou o registro siliclástico-evaporítico que corresponde à Formação Pedra de Fogo como sendo um sistema lacustre raso instalado durante o Permiano.
A Formação Motuca (Fig. 2) foi interpretada por Góes \& Feijó (1994) como a seção do Eotriássico cujas rochas foram depositadas em um ambiente desértico com lagos associados. O início da deposição dessa formação é marcado pela presença de espessas camadas de pelitos laminados que foram depositadas em um extenso sistema lacustre raso de baixa energia, com influxos terrígenos oriundos de rios efêmeros. Eventos regionais associados à Orogenia Allegheniana causaram isolamento e aumento na taxa de evaporação desses lagos. Tal mudança foi responsável pela progressiva substituição do sistema lacustre por um extenso ambiente desértico (Abrantes Júnior \& Nogueira 2013).

Por fim, ocupando o topo do Grupo Balsas, a Formação Sambaíba (Fig. 2) foi descrita por Vaz et al. (2007) como sendo composta por arenitos com granulometria fina a média e estratificação cruzada de grande porte, depositados a partir de extensas planícies arenosas que encobriram gradualmente os depósitos lacustres anteriores. A Formação Sambaíba marca a intensa desertificação do megacontinente Pangea durante o Triássico (Abrantes Júnior \& Nogueira 2013).

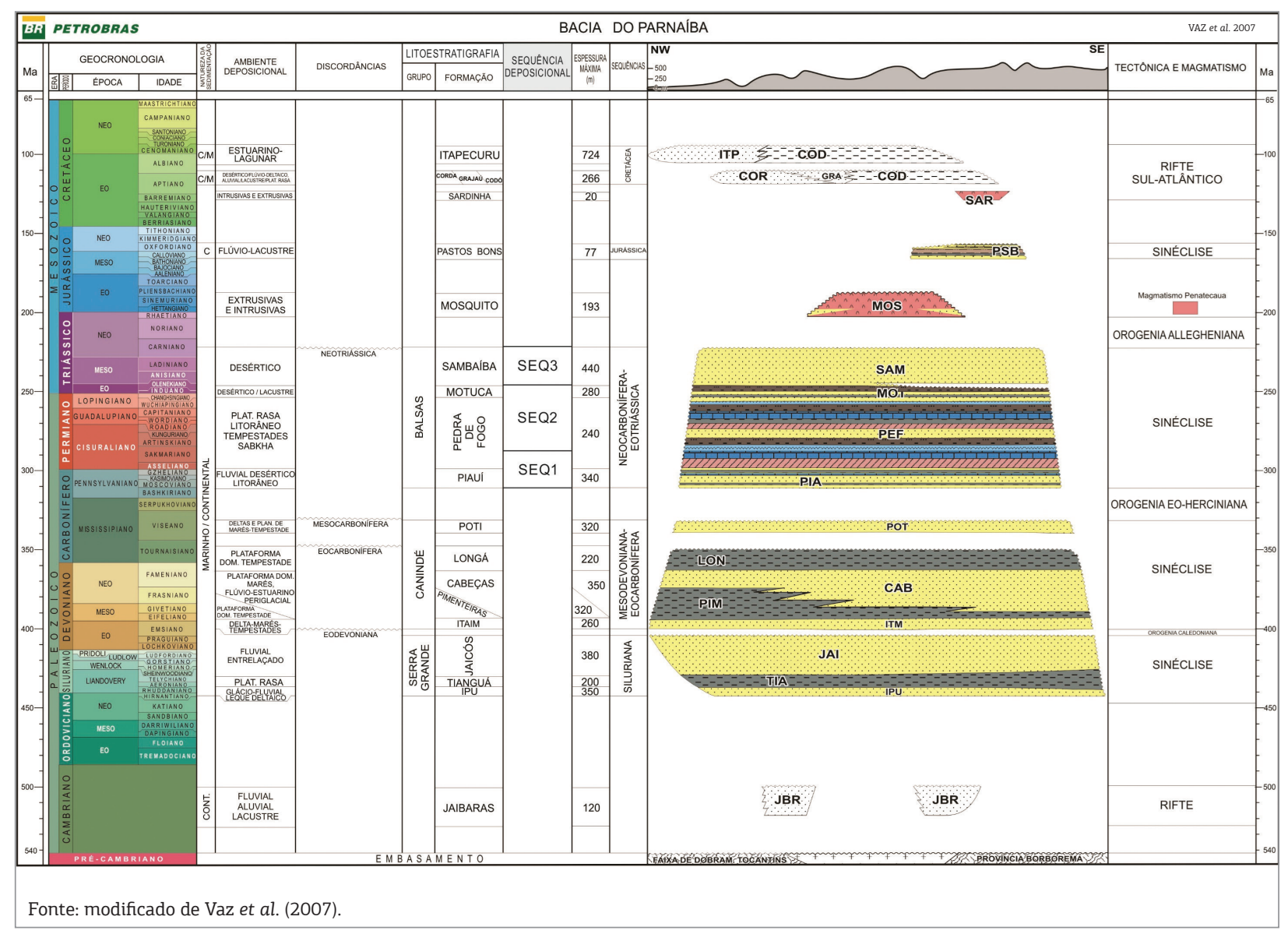

Figura 2. Carta estratigráfica da Bacia do Parnaíba. 


\section{ANÁLISE ESTRATIGRÁFICA}

\section{Análise 1D}

A análise estratigráfica $1 \mathrm{D}$ permitiu identificar três sequências deposicionais em cada um dos seis poços analisados. $\mathrm{Na}$ Sequência 1 foi possível reconhecer e delimitar quatro tratos de sistemas: o TSNB, o TST, o TSNA e o TSRF. $\mathrm{Na}$ Sequência 2 foram reconhecidos os três tratos de sistemas iniciais; não foi possível individualizar o TSRF. Por fim, a Sequência 3 está representada apenas pelo TSNB.

Nove superfícies-chave foram reconhecidas ao longo dessas três sequências, sendo quatro relacionadas às discordâncias que representam os limites de sequências (LS). Internamente, foram ainda identificadas duas Superfícies Regressivas Máximas (SRM1 e SRM2) e duas Superfícies Transgressivas Máximas (STM1 e STM2) nas duas sequências mais antigas (Sequências 1 e 2), além de uma Superfície Basal de Regressão Forçada (SBRF) na Sequência 1. O reconhecimento dessas superfícies baseia-se em mudanças nos padróes de empilhamento e na passagem brusca entre fácies (litologias) e sistemas deposicionais (associaçôes litofaciológicas).

\section{Sequência Deposicional 1}

Considerando-se as idades atribuídas às formaçōes do Grupo Balsas na carta estratigráfica da Bacia do Parnaíba (Goes \& Feijó 1994; Vaz et al. 2007), a deposição da Sequência Deposicional 1 (SEQ1) teve início no Neocarbonífero e se estendeu até o Mesopermiano, e compreende a Formação Piauí e parte da Formação Pedra de Fogo. Essa sequência é composta por TSNB, TST, TSNA e TSRF (Fig. 3) e o seu limite inferior (LS1) corresponde à Discordância Mesocarbonífera, descrita por esses autores.

O TSNB da SEQ1 é formado por vários ciclos fluviais, com espessura média de $22 \mathrm{~m}$, que apresentam um sutil afinamento textural para o topo. Cada ciclo inicia com espessas camadas de arenito na base, com média de $20 \mathrm{~m}$, sendo encobertas por delgados níveis de folhelho e, raramente, de siltito (Fig. 3).

Os ciclos que compóem esse trato de sistemas se agrupam para compor, nos poços estudados, um conjunto de ciclos que representa espaço de acomodação restrito, tendo sido representado nos perfis de poços analisados por um conjunto de ciclos em arranjo progradacional. De acordo com Wright \& Marriott (1993), o TSNB em um sistema fluvial é caracterizado por canais amalgamados e de granulometria mais grossa, com uma alta razão arenito/pelito. Essa sedimentação basicamente arenítica ocorre porque, em época de baixa criação de espaço de acomodação, os canais fluviais tendem a amalgamar, ocorrendo pouca ou nenhuma sedimentação de fácies de planície de inundação.
O fim da deposição do TSNB é marcado pela presença de uma delgada camada de calcário ou evaporito com cerca de $3 \mathrm{~m}$ de espessura, referente ao TST acima, que representa a primeira incursão marinha nessa sequência (Fig. 3). Nesse ponto, que representa a passagem de um sistema fluvial para um sistema litorâneo, foi posicionada a SRM1 que separa o TSNB do TST, que se estabeleceu a seguir.

Nos poços analisados, o TST é composto por ciclos que, no geral, exibem um padrão de engrossamento textural para o topo, os quais iniciam com camadas de folhelho ou argilito e terminam com camadas de arenito ou calcarenito. Um padráo de aumento de aridez para o topo foi interpretado para os ciclos que terminam com camadas de evaporito e, portanto, não podem ser classificados como engrossamento ou afinamento textural (Fig. 3).

Neste trato (TST), contudo, os ciclos estão arranjados de forma a compor um conjunto, que exibe um padrão de empilhamento retrogradacional, indicado pela deposição de fácies cada vez mais distais. Interpreta-se que a sedimentação desse trato de sistemas ocorreu em um ambiente marinho raso.

A STM1 limita o TST do TSNA que se segue, e foi posicionada em um nível de folhelho que apresenta os maiores valores de resposta no perfil de raios gama e marca a mudança no padrão de empilhamento retrogradacional (TST) para progradacional (TSNA) (Fig. 3). Esses níveis de folhelho mais radioativos encontram-se associados a camadas de calcários interpretadas como depósitos marinhos mais distais.

O TSNA da SEQ1 representa o final da deposição marinha durante a evolução da Sequência Neocarbonífera-Eotriássica estudada. Os ciclos que compóem esse trato de sistemas apresentam uma tendência de engrossamento textural para o topo e iniciam, na base, com folhelhos ou siltitos, terminando com arenitos, calcários ou dolomitos. A progressiva regressão da linha de costa associada a um aumento na aridez da regiáo causou uma forte tendência de deposição de sedimentos evaporíticos. Tal fato é refletido nos ciclos que passam a culminar em espessas camadas de anidrita, algumas delas alcançando $20 \mathrm{~m}$ de espessura, indicando um acentuado aumento de aridez para o topo (Fig. 3).

Os conjuntos de ciclos que compóem esse trato de sistemas apresentam um padrão de empilhamento progradacional, representado no perfil do poço por fácies de caráter mais proximal em direção ao topo.

A SBRF marca o limite superior do TSNA, e encerra a sedimentação da fase de regressão normal da SEQ1. Essa superfície foi posicionada nos perfis estudados com base nas mudanças bruscas de fácies, representadas pela passagem de espessas camadas de anidrita, depositadas em um ambiente marinho raso atribuído ao TSNA, para litofácies essencialmente siliciclásticas, interpretadas como produto de um ambiente deltaico que se estabeleceu durante o TSRF. 
O TSRF é caracterizado por ciclos deltaicos com padrão de engrossamento textural para o topo, os quais iniciam com camadas de folhelho ou siltitos na base e terminam com camadas de arenito no topo ou, localmente, um calcário.

Os ciclos que compóem esse trato de sistemas formam conjuntos de ciclos com padrão de empilhamento progradacional, caracterizados por um aumento gradual nos intervalos arenosos (possíveis fácies de frente deltaica) em relação aos pelíticos (fácies de prodelta) desde o início até o término do TSRF.

A porção superior do TSRF é caracterizada por uma maior quantidade de camadas de arenito, que podem representar barras de desembocadura de frente deltaica, as quais se encontram sobrepostas discordantemente por uma sucessáo de delgadas camadas de calcário e pelito.

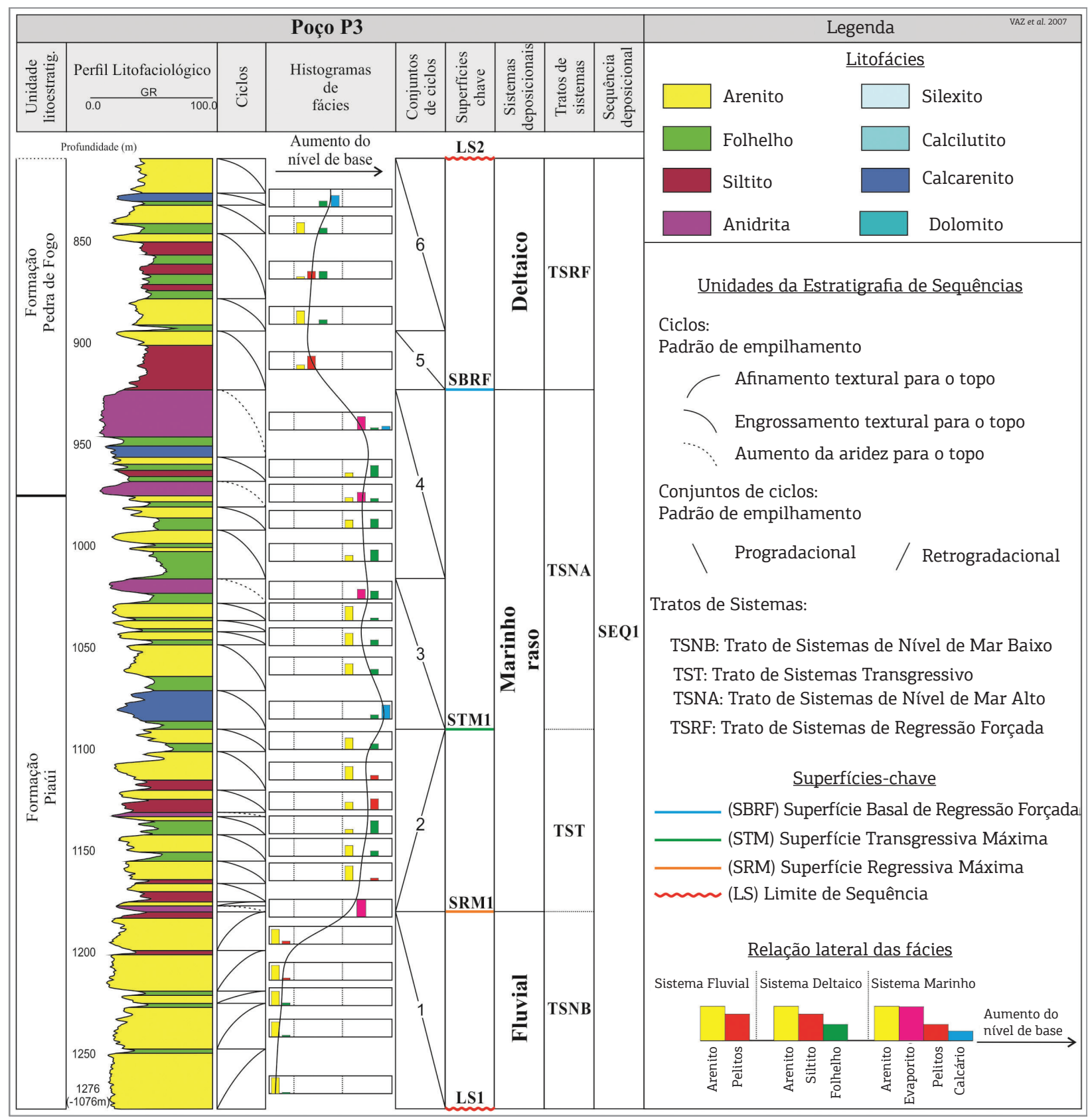

Figura 3. Intervalo do diagrama 1D do poço P3 correspondente ao intervalo da Sequência Deposicional 1 mostrando o perfil litofaciológico, os ciclos, os histogramas de fácies, os conjuntos de ciclos, as superfícies-chave, os sistemas deposicionais e os tratos de sistemas interpretados. Localização do poço P3 representada na Figura 1. 
Essa mudança marcante de fácies registra a transição do sistema deltaico, que representa o TSRF da SEQ1, para um ambiente lacustre/desértico com sabkhas associadas, relacionado ao início da deposição da SEQ2, sobre discordância Neopermiana (LS2).

\section{Sequência Deposicional 2}

A SEQ2 foi depositada durante Neopermiano e o Eotriássico e corresponde litoestratigraficamente ao topo da Formação Pedra de Fogo e à Formação Motuca por completo. Foram reconhecidas para essa sequência três tratos de sistemas: o TSNB, o TST e o TSNA (Fig. 4).

Ao longo de toda a sucessão que caracteriza a SEQ2, a quantidade de rochas evaporíticas e carbonáticas diminui gradativamente em direção ao topo. Essa diminuição está relacionada a mudanças nas condiçóes climáticas regionais, responsáveis pela redução da aridez, como também pela progradação de sistemas proximais, como o lacustre e o desértico entre o Permiano e o Triássico, relacionada à contínua continentalização da bacia.

De uma maneira geral, o TSNB da SEQ2 é representado predominantemente por ciclos de aumento da aridez para o topo, os quais iniciam com rochas carbonáticas ou folhelhos na base e terminam com camadas de evaporito no topo (Fig. 4). Tais ciclos foram agrupados em um conjunto de ciclos que expressam esse momento de maior aridez dessa sequência. Tal conjunto foi denominado aqui de progradacional.

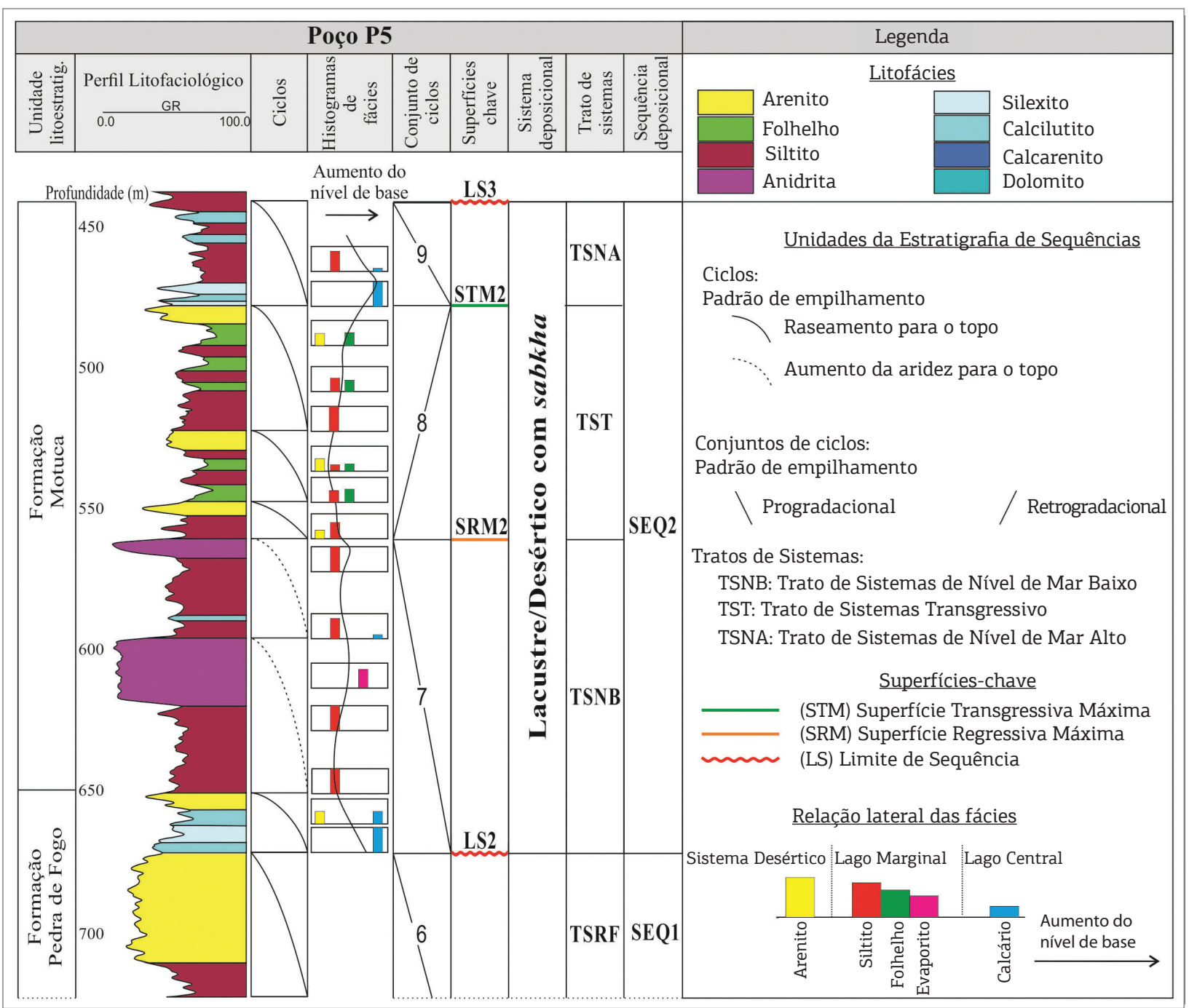

Figura 4. Intervalo do diagrama 1D do poço P5 correspondente ao intervalo da Sequência Deposicional 2 mostrando o perfil litofaciológico, os ciclos, os histogramas de fácies, os conjuntos de ciclos, as superfícies-chave, o sistema deposicional e os tratos de sistemas interpretados. Localização do poço P5 representada na Figura 1. 
A SRM2 marca o limite superior do TSNB da SEQ2. Essa superfície foi posicionada no intervalo em que foi observada, nos perfis analisados, a última camada de evaporito. Acima da SRM2, o conjunto de ciclos deixa de ser progradacional e passa a ser retrogradacional associado ao TST.

O TST da SEQ2 é composto por ciclos de raseamento para o topo, os quais iniciam com camadas de folhelho ou siltito e culminam, no topo, em delgadas camadas de arenito. A presença dessas camadas de arenito ao longo dos ciclos de raseamento é sugestiva do aporte de sedimentos de granulometria aparentemente mais grossa trazidos por rios efêmeros. O conjunto de ciclos que compóe esse trato de sistemas é retrogradacional, caracterizado por um aumento de camadas de calcário para o topo (Fig. 4).

A STM2 limita superiormente a deposiçāo do TST e foi posicionada na base de uma significante camada de calcário (com cerca de $6 \mathrm{~m}$ ), a qual representa a deposiçáo nas porçôes centrais e mais distais do sistema lacustre. Esse limite marca a mudança no padráo de empilhamento de retrogradacional para progradacional (Fig. 4).

O TSNA da SEQ2 é formado basicamente por litofácies siliciclásticas e raramente por litofácies carbonáticas (Fig. 4). O TSNA é composto por ciclos de raseamento para o topo e inicia com camadas de folhelho, terminando com camadas de arenito ou siltito.

O conjunto de ciclos que compóe o TSNA exibe padrão progradacional, indicado pela deposição de fácies com caráter mais proximal em direção ao topo, em que foram depositados, em proporçóes cada vez maiores, arenitos associados a sistemas desérticos.

O TSNA encerra a deposiçấo sedimentar da SEQ2, a qual é limitada pela superfície erosiva LS3, formada durante $\mathrm{o}$ Eotriássico. Como mencionado, $\mathrm{o}$ TSRF não foi individualizado nessa sequência e seu registro pode estar associado à porçáo superior do TSNA.

\section{Sequência Deposicional 3}

A SEQ3 encerra a deposição da Sequência NeocarboníferaEotriássica e representa o final de um grande ciclo regressivo. Tal sequência registra o término da sedimentaçâo de origem marinha/costeira e continental lacustre na bacia a partir da instalação de um deserto, materializado pelos arenitos da Formação Sambaíba.

Nessa sequência foi reconhecido apenas o TSNB, o qual é composto predominantemente por arenitos, com folhelhos e siltitos subordinados (Fig. 5). Os ciclos são de engrossamento textural para o topo, sendo formados na base por camadas de folhelho e/ou siltito, interpretadas como fácies de interdunas, que gradam, em direção ao topo, para espessas camadas de arenito que devem representar depósitos de dunas eólicas, podendo alcançar até $300 \mathrm{~m}$.
Embora o contexto deposicional dessa sequência seja o desértico, observa-se que no topo dos conjuntos de ciclos ocorrem com mais frequência fácies areníticas, ao passo que as pelíticas se encontram cada vez mais raras. Tal fato permitiu interpretar que o padrão de empilhamento desse trato de sistemas seja progradacional (Fig. 5), apesar de a SEQ3 ser considerada uma sequência continental de ambiente desértico e tal padráo poder estar relacionado à paulatina queda do nível freático.

O limite superior da SEQ3 coincide com a discordância Eotriássica descrita por Vaz et al. (2007) e encerra a deposiçẫo na Sequência Neocarbonífera Eotriássica dessa bacia.

\section{Análise 2D}

A análise $2 \mathrm{D}$ envolveu a análise sismoestratigráfica e a confecção de uma seção de correlação, as quais permitiram rastrear lateralmente as superfícies-chave reconhecidas na análise $1 \mathrm{D}$ dos poços, além das unidades genéticas da estratigrafia de sequências. Nas seçôes sísmicas analisadas foi possível reconhecer sete refletores expressivos, que apresentaram maiores amplitudes e exibiram uma boa continuidade lateral. Tais refletores referem-se aos limites de sequências (LS1, LS2, LS3 e LS4) e às SRM, STM e a SBRF da SEQ1 (Fig. 6; Apêndices 1, 2 e 3).

As sismofácies reconhecidas nas seçóes sísmicas foram as de configuraçáo paralela a subparalela. De uma maneira geral, os refletores que constituem as sismofácies comportam-se de maneira bastante constante em toda a seção sísmica.

Os padrôes de sismofácies das sismossequências reconhecidas nas seçôes sísmicas podem ser interpretados como tendo sido formados em um ambiente em que a taxa de sedimentaçáo se manteve constante, compatível com o contexto de sinéclise em que a sequência estudada foi depositada.

Com relaçấo às terminaçôes dos refletores nas superfícies-chave (discordâncias e superfícies de regressão e transgressão máximas), não foi reconhecido nenhum padrão discordante (seja de truncamento erosional ou aparente ou do tipo lapout-onlap, downlap ou toplap), sendo dominante o padrão concordante (Fig. 6).

Também foi elaborada uma seção de correlação estratigráfica na etapa de análise 2D (Fig. 7). Essa seção tem sentido aproximado E-W (Fig. 1) e o seu principal objetivo foi avaliar o comportamento das unidades genéticas e rastrear as superfícies cronoestratigráficas identificadas nos poços. De uma maneira geral, foi possível observar uma boa continuidade lateral das litofácies depositadas em cada trato de sistemas. $\mathrm{O}$ datum utilizado para essa seção foi a superfície transgressiva máxima da SEQ1.

No TSNB da SEQ1 é possível observar a presença de uma grande quantidade de espessas camadas de arenito e delgados níveis de folhelho, visualizados nos perfis aqui 
analisados (Fig. 7). Esse trato de sistemas corresponde litoestratigraficamente à porçáo basal da Formação Piauí, a qual foi descrita por Lima \& Leite (1978) como correspondente a um sistema fluvial, com contribuição eólica e breves incursóes marinhas, em clima semiárido a desértico. Trabalhos mais recentes, como o de Ribeiro (2000), interpretaram essa unidade como tendo sido depositada em um sistema fluvial com canais entrelaçados rasos. Nesse sistema deposicional, os níveis de folhelho são interpretados como tendo sido depositados em áreas externas aos canais, em efêmeras planícies de inundação lamosas. Ainda segundo esse autor, dados de paleocorrentes para a referida unidade indicam um sentido preferencial para o norte e um elevado grau de desvio padrão na direção do paleofluxo, o que seria coerente com a presença de rios formados por múltiplos canais, como os de estilo entrelaçado.

A Fig. 8 mostra os perfis litofaciológicos dos poços P2, P3 e P6 (porção oeste, central e leste, respectivamente), compreendendo o TSNB da SEQ1, em que é possível observar uma alta razão arenito/folhelho. Tal fato sugere que esses

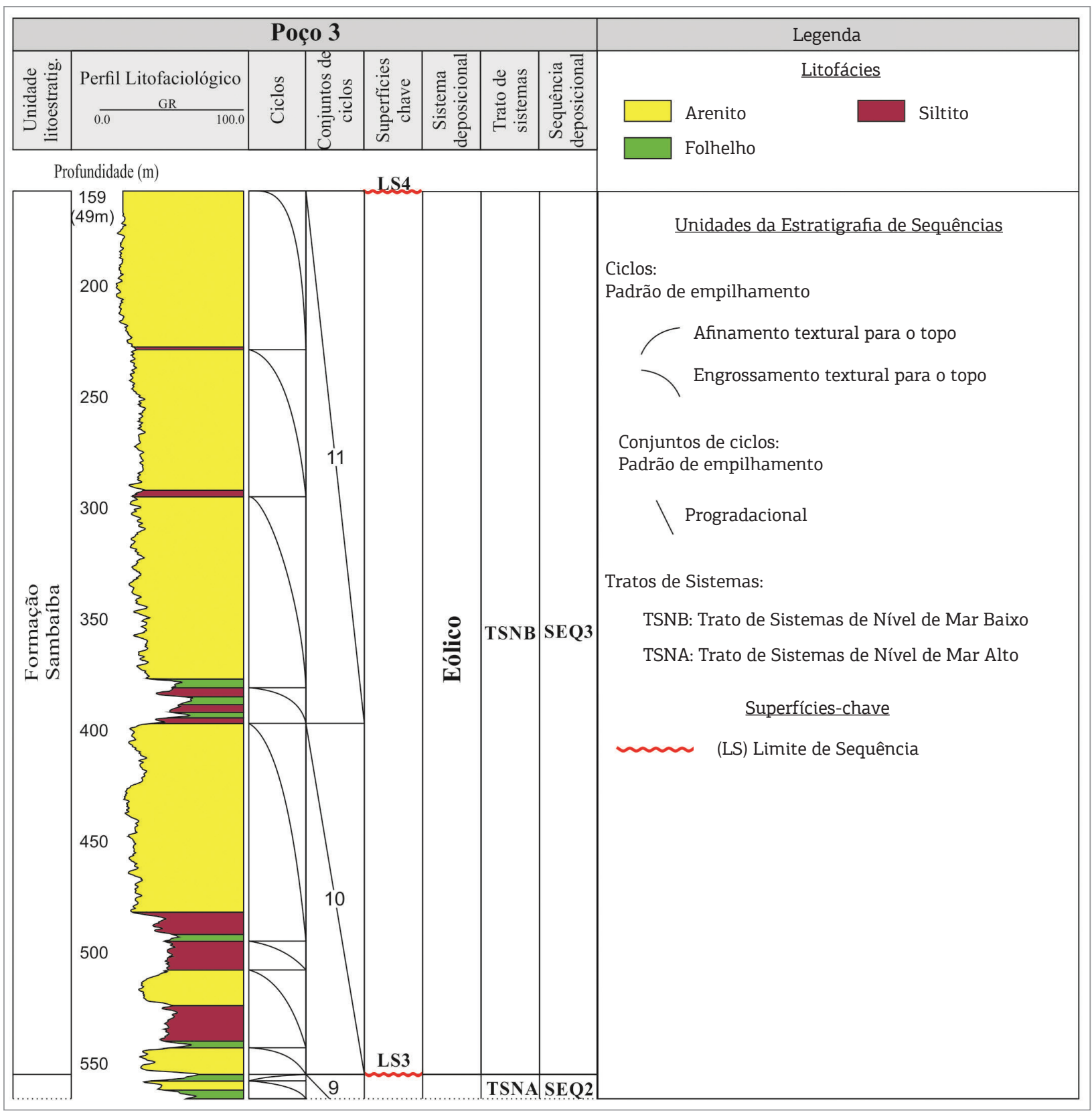

Figura 5. Intervalo do diagrama 1D do poço P3 correspondente ao intervalo da Sequência Deposicional 3 mostrando o perfil litofaciologico, os ciclos, os conjuntos de ciclos, as superfícies-chave, os sistemas deposicionais e o trato de sistema interpretado. Localização do poço P3 representada na Figura 1. 
rios possuíam canais amalgamados, o que é considerado uma característica marcante do TSNB, em que o espaço de acomodação é restrito e os rios são predominantemente do tipo entrelaçado, os quais depositam areias relativamente grossas no fundo dos vales incisos escavados durante a queda do nível de base.

Na Fig. 8 também é possível observar que a razão arenito/folhelho é maior na região do poço P3, que fica um pouco mais a sul que os demais e encontra-se posicionado na região central. Tal fato corrobora os dados de paleocorrentes de Ribeiro (2000), que indicam um paleofluxo para norte. Para tal, foi levado em consideraçáo que os depósitos estáo relacionados aos mesmos canais fluviais em todos os poços.

No TST da SEQ1 é possível observar que há um aumento significativo na quantidade de depósitos siliciclásticos na região do poço $\mathrm{P}$ 3, localizado na porção central e mais a sul em relação aos demais poços (Fig. 9). Em P1 e P2 (região oeste; Fig. 7) há uma grande variabilidade litofaciológica (fácies clásticas, evaporíticas e carbonáticas), enquanto na regiáo dos poços P4, P5 e P6 ocorre uma diminuição considerável na quantidade de arenito e um aumento na quantidade de folhelhos e rochas carbonáticas (Fig. 7).

Como essas fácies sedimentares estão relacionadas a um ambiente marinho/costeiro, tal fato leva a inferir que o poço P3 está localizado no que seria um ambiente costeiro ou desértico com sabkhas associadas (também sugerido pela presença de finas camadas de anidrita); os poços P1 e P2, por apresentarem grande variabilidade litológica, poderiam estar posicionados em uma zona marinha rasa, ao passo que os poços P4, P5 e P6 estariam em uma porção

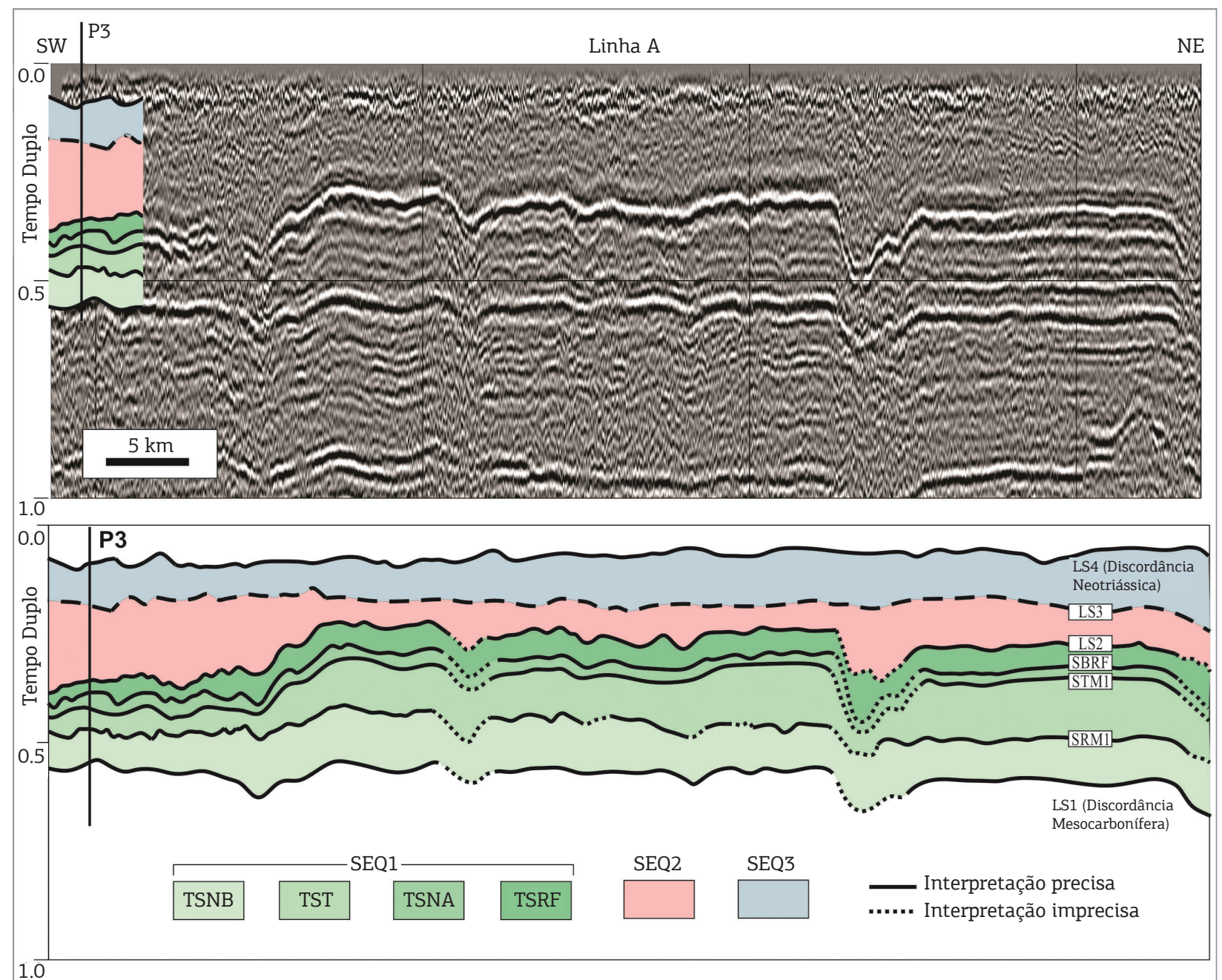

$1 . \overline{0}$

TSNB: Trato de Sistemas de Nível Baixo; TST: Trato de Sistemas Transgressivo; TSNA: Trato de Sistemas de Nível Alto; TSRF: Trato de Sistemas de Regressão Forçada; SEQ: Sequência Deposicional.

Figura 6. Seção sísmica A exibindo as superfícies estratigráficas interpretadas em um intervalo de 0 a $1.0 \mathrm{~s}$. Localização da seção sísmica A representada na Figura 1. 
mais distal, pois apresentam, na sua maioria, folhelhos e calcários (Figs. 7 e 9).

No TSNA da SEQ1 é possível observar que os poços que pertencem à porção oeste da área de estudo (P1 e P2; Fig. 7) são os que apresentam, no perfil, a menor quantidade de rochas siliciclásticas. Além disso, esses poços, com o poço $\mathrm{P} 3$, são os que apresentam a maior quantidade de evaporitos (Fig. 10). Tal fato sugere que a regiáo dos poços P1 e P2 (porção oeste) estaria em uma porção mais distal em relação às demais regióes.

O TSRF da SEQ1 mostra, dentre os poços analisados, uma maior espessura na região dos poços P4 e P5 (Fig. 7). Além disso, observa-se que esses poços apresentam um espesso pacote de arenito no topo desse trato de sistemas, o qual não ocorre nos poços P1 e P2 (Figs. 7 e 11). A não ocorrência desses pacotes de arenito na regiáo oeste (poços P1 e P2), bem como a sua ocorrência em maior expressão na região leste (poço P6), pode ser justificada pelo fato de eles terem sido removidos durante o episódio de erosão relacionado à geração da discordância-limite superior dessa sequência.
No TSNB da SEQ2, a quantidade de rochas carbonáticas e evaporíticas diminui significativamente para o leste, em que foram depositados sedimentos que deram origem preferencialmente a rochas siliciclásticas (arenitos, folhelhos e siltitos; Figs. 7 e 12). Esse fato está claramente evidenciado na sucessão de rochas do poço P6. Essa característica permite inferir que os poços P1 e P2 estariam localizados na regiáo central de um lago, enquanto os poços P3, P4, P5 e P6, em uma porção marginal.

No TST da SEQ2 é possível observar um aumento significativo na espessura desse trato de sistemas para a regiāo leste da área de estudo. Além disso, a quantidade de arenito e siltito aumenta no mesmo sentido, enquanto a quantidade de folhelhos diminui (Figs. 7 e 13). Tal fato permite inferir que os poços P1 e P2 estariam em uma posição mais central de um lago, em que foi depositada uma maior quantidade de folhelhos e calcários, enquanto os poços P3, P4, P5 e P6 estariam em uma porção mais marginal, recebendo influência de rios efêmeros e sedimentos eólicos.

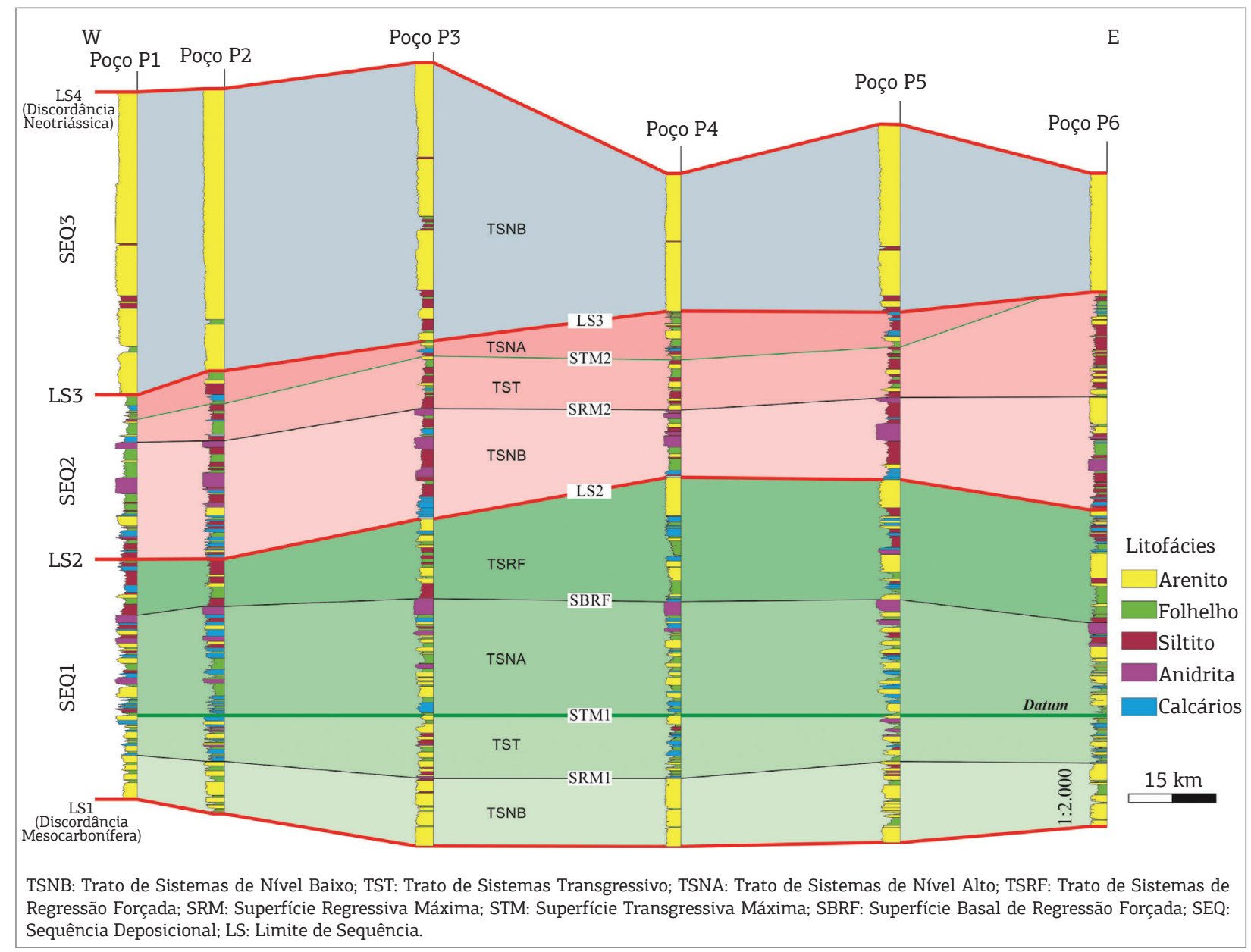

Figura 7. Seção de correlação mostrando a continuidade das sequências deposicionais e dos seus tratos de sistemas. Localização da seção de correlação e dos poços na Figura 1. 
A variação litofaciológica observada no TSNA da SEQ2 é pequena, sendo tal trato composto principalmente por sedimentos siliciclásticos. Além disso, a superfície que limita a SEQ2 está muito bem evidenciada na porção mais NE da área de estudo (poço P6; Fig. 7). Vaz et al. (2007) afirmam que a passagem entre as formaçóes Motuca e Sambaíba, que corresponde ao limite entre a SEQ2 e a SEQ3 (LS3), ocorre de forma gradual, podendo também ser localmente brusca. Os mesmos autores sugerem ainda a existência de uma discordância na porção SE da bacia. Esse contato erosivo foi identificado apenas no poço P6, localizado na porção mais leste da área de estudo (Fig. 7). Dessa forma, o LS3 foi interpretado como uma discordância erosiva na porção mais leste da área, a qual evolui para uma concordância correlativa no restante da área.

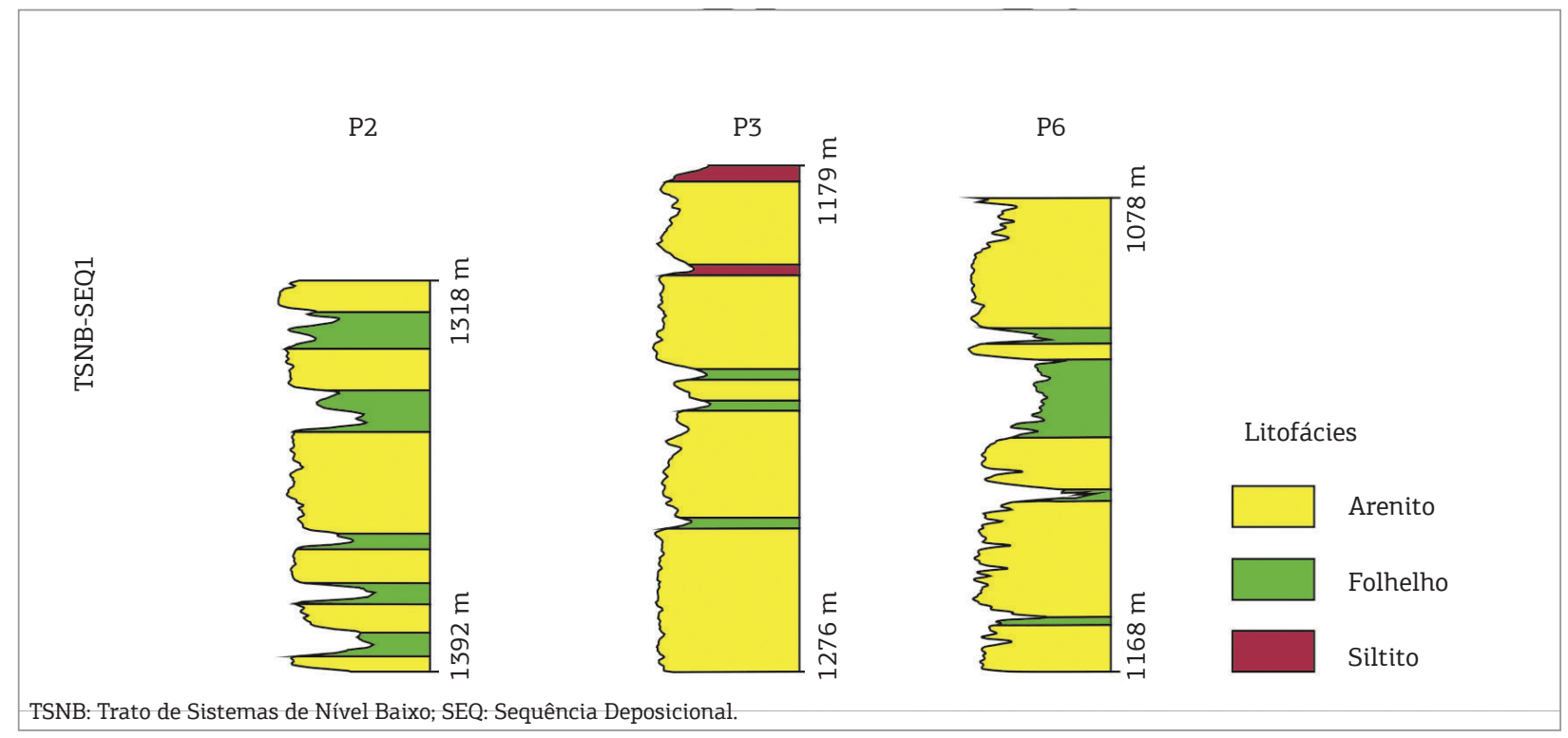

Figura 8. Perfil litofaciológico dos poços P2, P3 e P6, compreendendo o Trato de Sistemas de Nível Baixo da Sequência Deposicional 1. Localização dos poços representada na Figura 1.

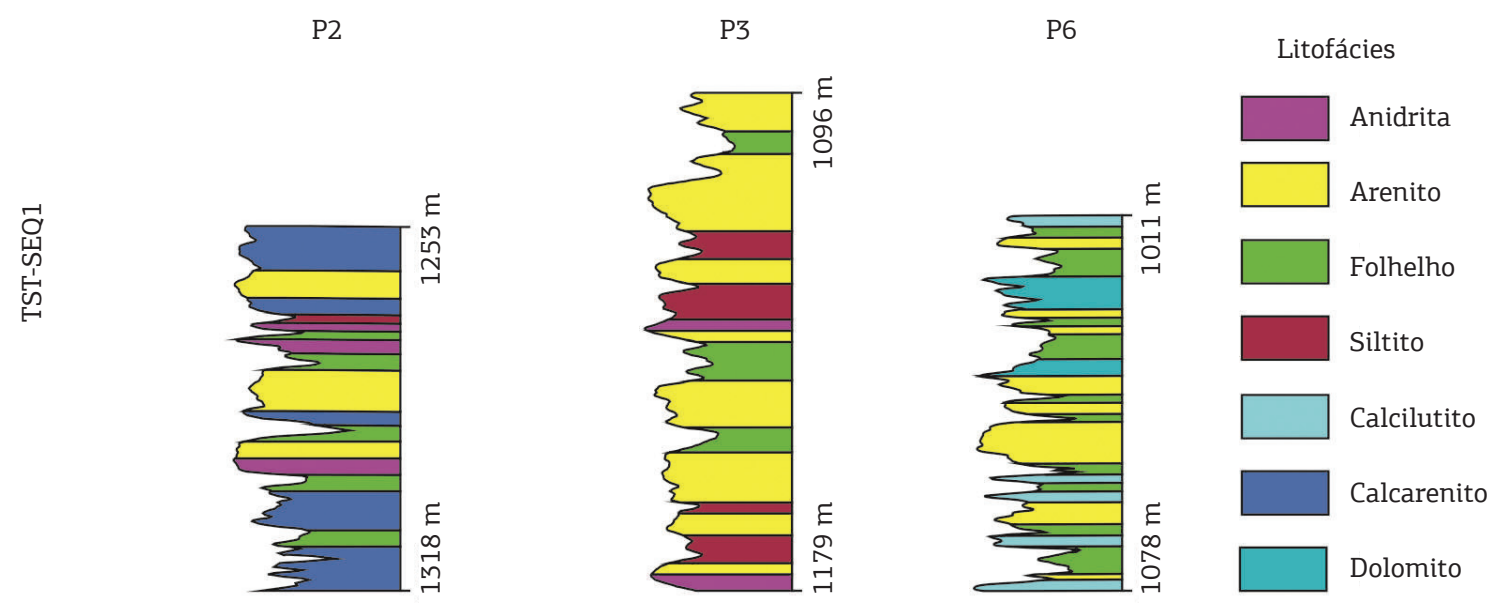

TST: Trato de Sistemas Transgressivo; SEQ: Sequência Deposicional.

Figura 9. Perfil litofaciológico dos poços P2, P3 e P6, compreendendo o Trato de Sistemas Transgressivo da Sequência Deposicional 1. Localização dos poços representada na Figura 1. 


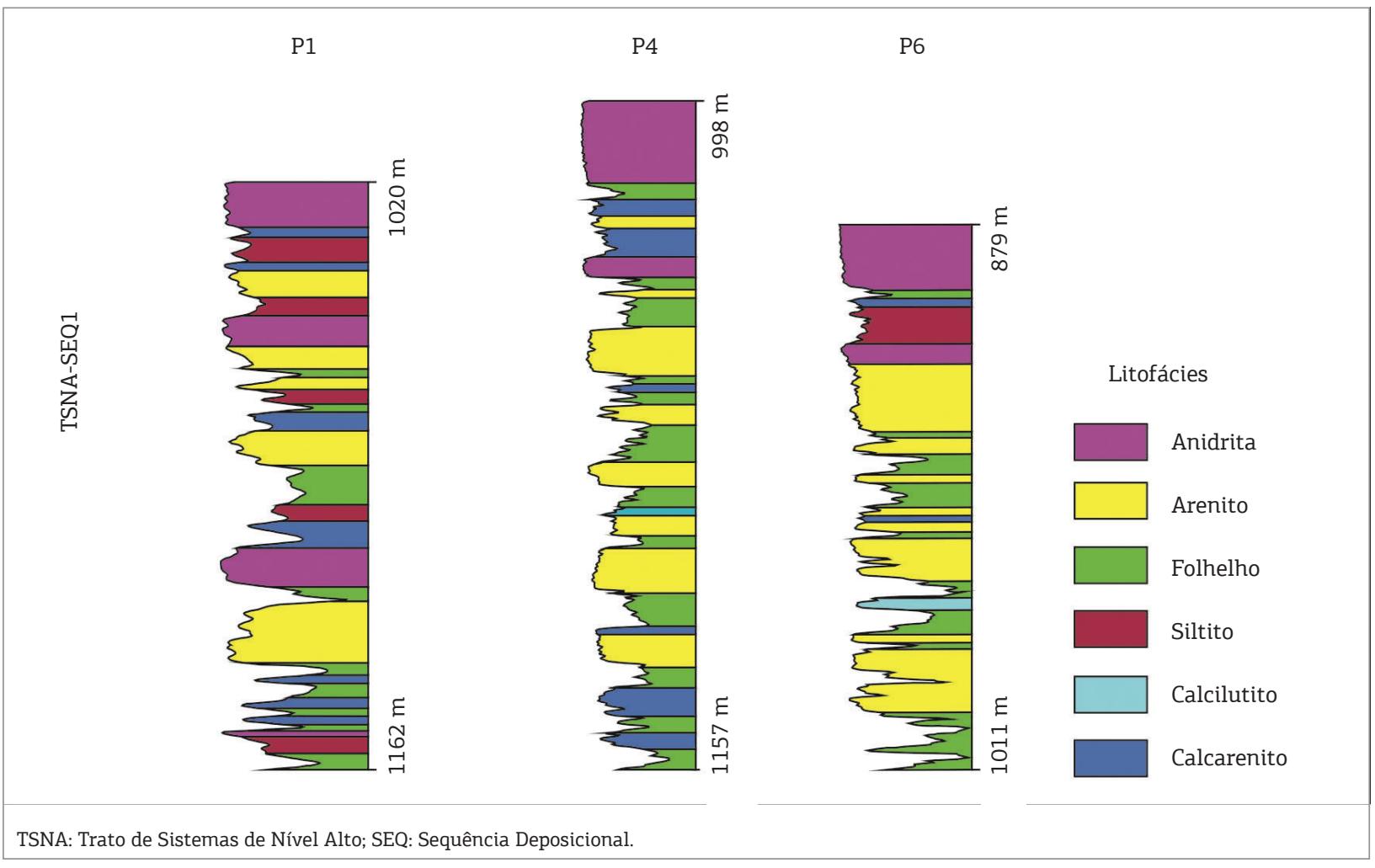

Figura 10. Perfil litofaciológico dos poços P1, P4 e P6, compreendendo o Trato de Sistemas de Nível Alto da Sequência Deposicional 1. Localização dos poços representada na Figura 1.

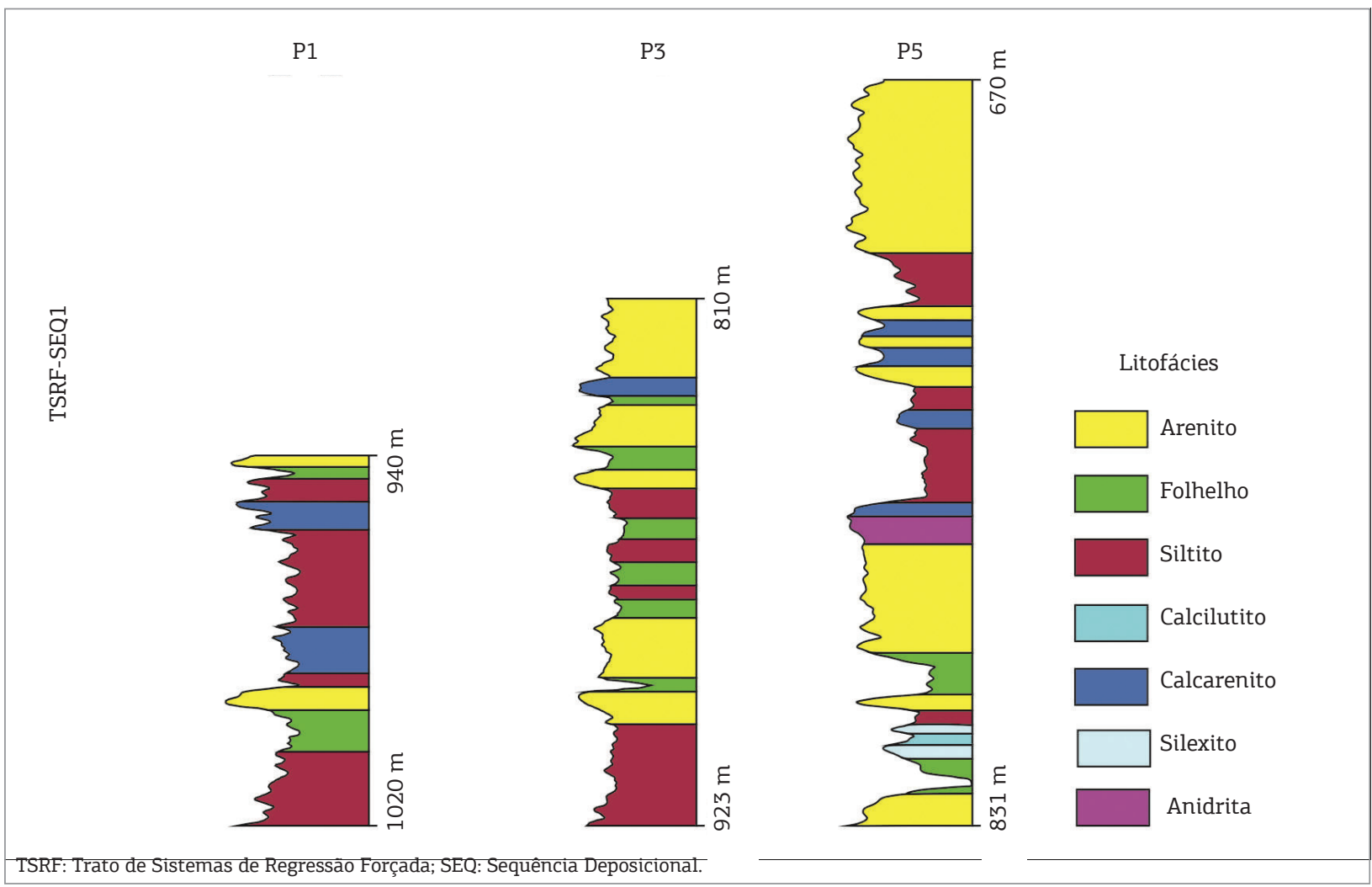

Figura 11. Perfil litofaciológico dos poços P1, P3 e P5, compreendendo o Trato de Sistemas de Regressão Forçada da Sequência Deposicional 1. Localização dos poços representada na Figura 1. 


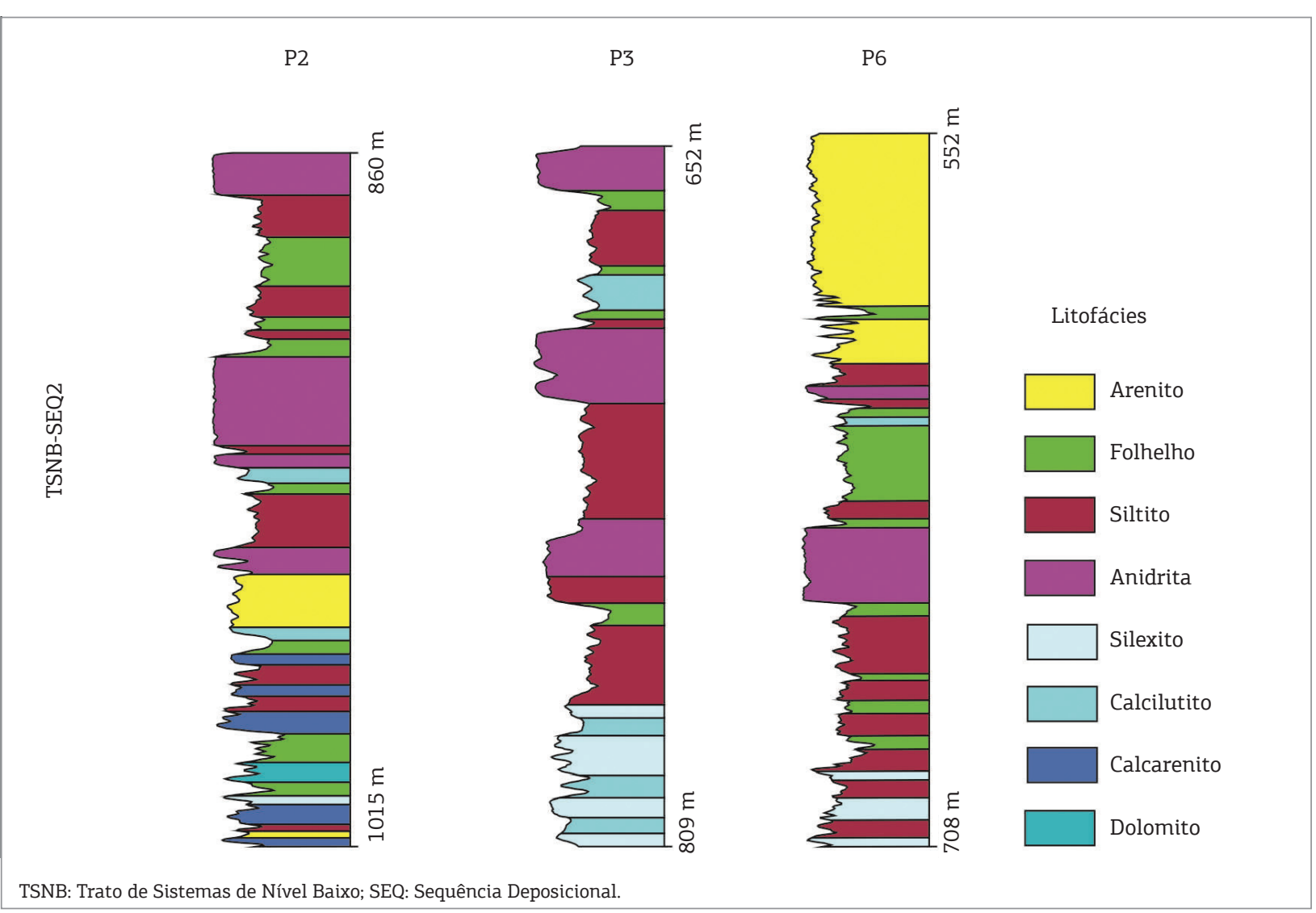

Figura 12. Perfil litofaciológico dos poços P2, P3 e P6, compreendendo o Trato de Sistemas de Nível Baixo da Sequência Deposicional 2. Localização dos poços representada na Figura 1.

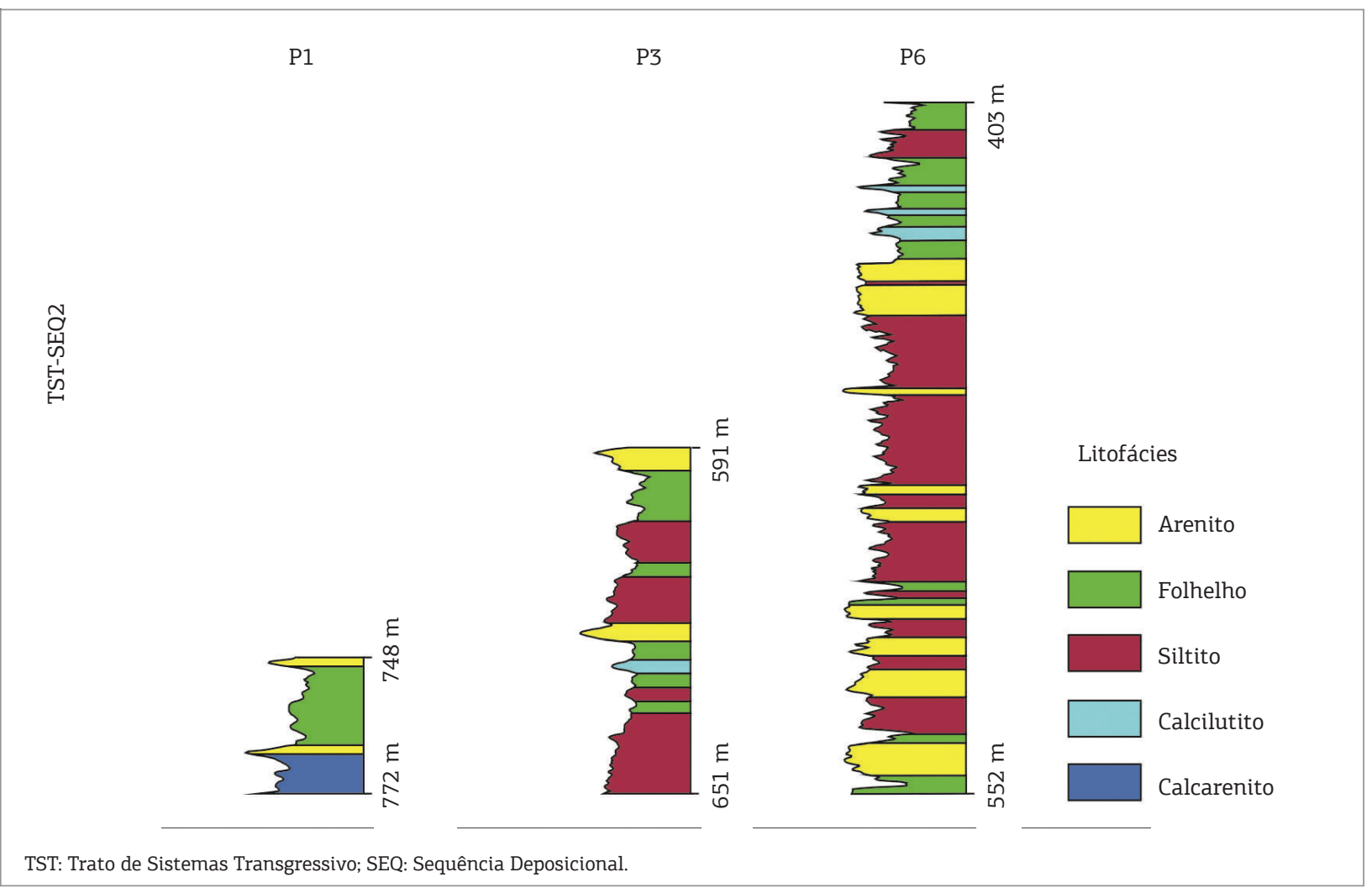

Figura 13. Perfil litofaciológico dos poços P1, P3 e P6, compreendendo o Trato de Sistemas Transgressivo da Sequência Deposicional 2. Localização dos poços representada na Figura 1. 


\section{SÍNTESE ESTRATIGRÁFICA}

Neste item serão apresentados e discutidos os modelos evolutivos estratigráficos idealizados para a seção estudada, a partir da interpretação dos dados analisados neste trabalho. Os modelos de evolução para as SEQ1, SEQ2 e SEQ3 estão representados nas Figs. 14, 15 e 16, respectivamente.

A SEQ1 (Fig. 14) teve sua deposição iniciada durante o Neocarbonífero. A porção basal dessa sequência, que corresponde ao TSNB, está relacionada à deposição de sedimentos siliciclásticos em um sistema fluvial com canais entrelaçados. De uma maneira geral, a alta razão arenito/folhelho nesses depósitos sugere a presença de canais amalgamados, formados em contexto de pouco espaço de acomodação com sedimentação eólica associada. O paleofluxo dos antigos canais desse sistema indica uma direção aproximadamente norte, o que estaria bem representado pela diminuição da quantidade de arenito nos perfis localizados naquela direção.

Ainda durante o Neocarbonífero ocorreu uma transgressão marinha, materializada pela passagem de fácies fluviais para fácies depositadas em um ambiente marinho raso. Inicia-se, nesse momento, o TST da SEQ1. Nesse período foram depositados os primeiros sedimentos carbonáticos e evaporíticos do registro Paleozoico da bacia (Fig. 14).
O intervalo de tempo que compreende o fim do Carbonífero e o início do Permiano é marcado pela deposição de sedimentos mistos (evaporíticos, carbonáticos e siliciclásticos), ainda em ambiente marinho raso. Nesse período foi depositado o TSNA da SEQ1, cuja etapa final da sedimentação foi marcada pela progressiva regressão da linha de costa associada a um aumento na aridez da regiāo, causando, assim, uma forte tendência de deposição de sedimentos evaporíticos (Fig. 14).

Por fim, o TSRF da SEQ1 é interpretado como formado por depósitos deltaicos, constituídos principalmente por sedimentos siliciclásticos; no entanto, calcários e evaporitos também podem ocorrer (Fig. 14).

A deposição da SEQ2 (Fig. 15) iniciou-se ainda no Permiano e a sua fase inicial, representada pelo TSNB, é caracterizada por sedimentos siliciclásticos, carbonáticos e evaporíticos depositados provavelmente em sistema lacustre com sabkhas associadas. Durante a deposição desse trato de sistemas ocorre o último registro de sedimentos evaporíticos dessa sequência e, a partir de então, a sedimentação passa a ser predominantemente siliciclástica, com raras camadas de rochas carbonáticas.

No TST da SEQ2 foram depositados sedimentos carbonáticos de maneira muito menos significativa, quando

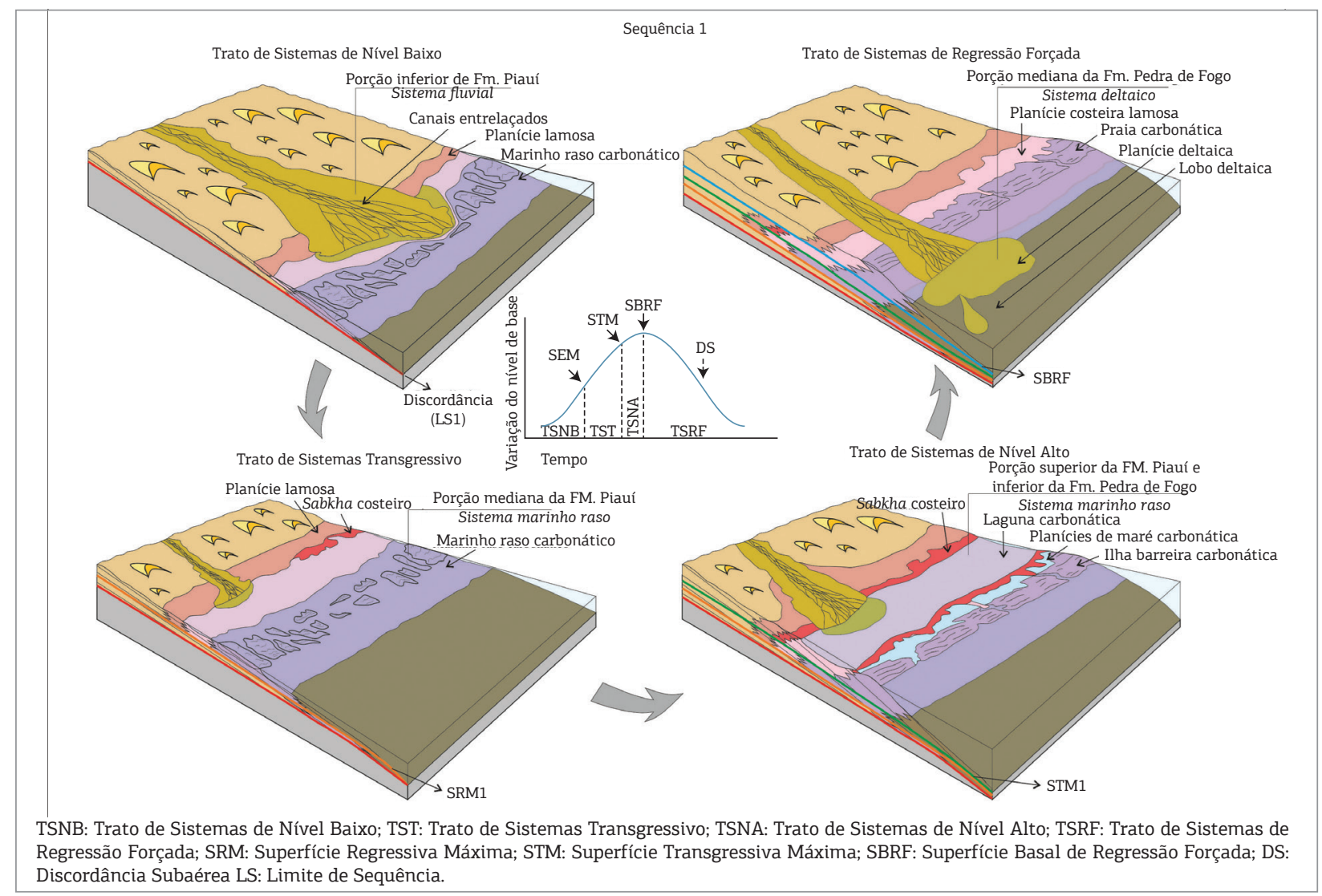

Figura 14. Modelos estratigráficos evolutivos idealizados para a Sequência 1. 


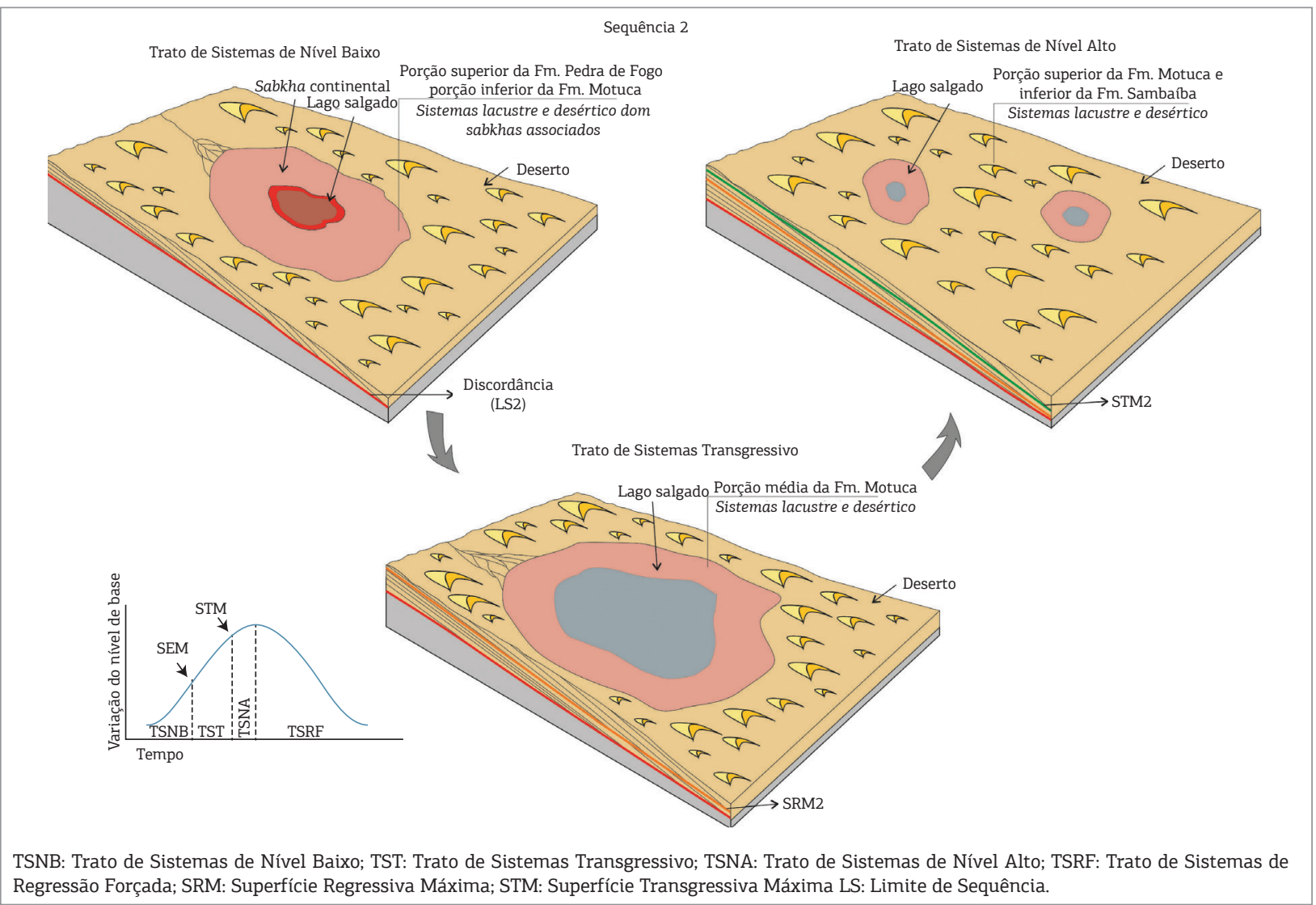

Figura 15. Modelos estratigráficos evolutivos idealizados para a Sequência 2.

Sequência 3

Trato de Sistemas de Nível Baixo

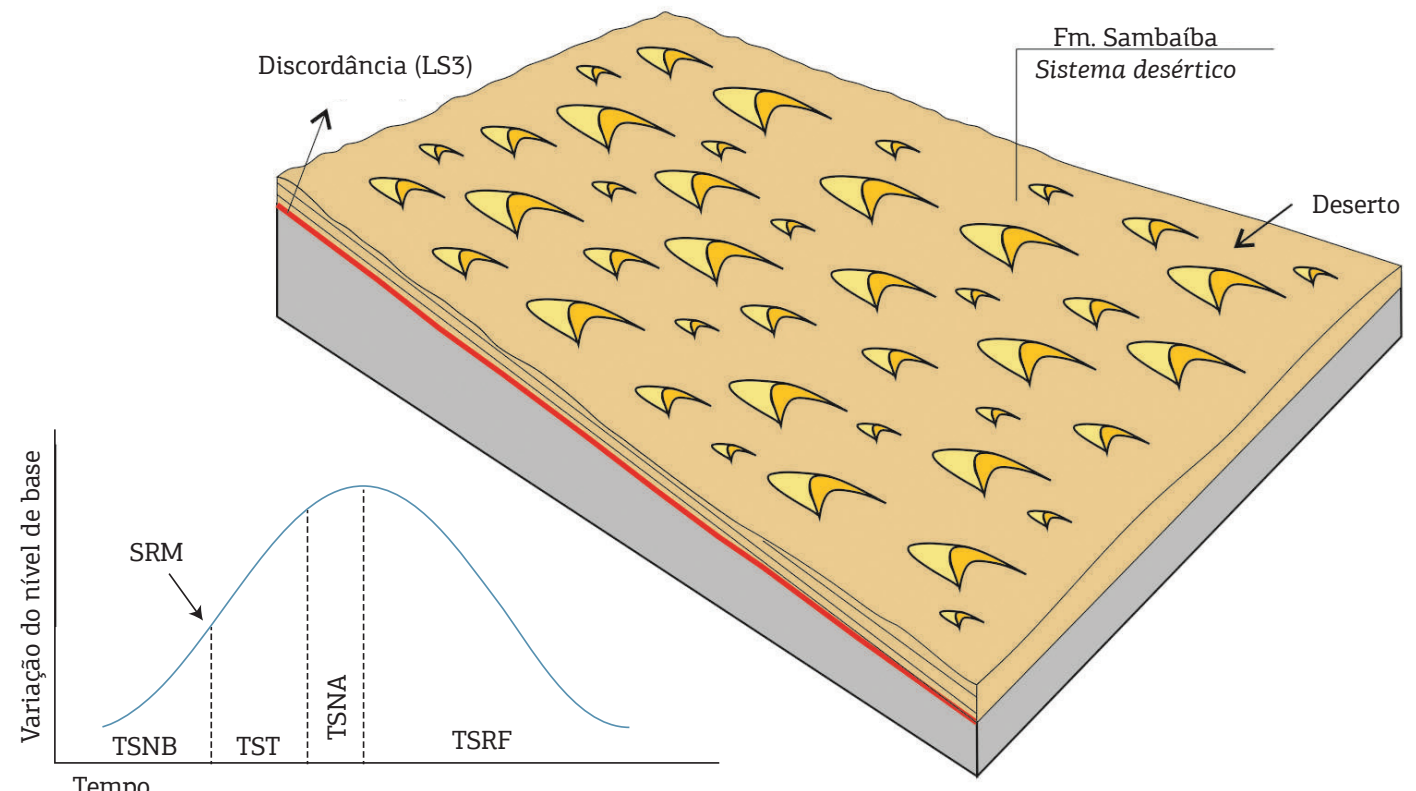

SRM: Superfície Regressiva Máxima; TSNB: Trato de Sistemas de Nível Baixo; TST: Trato de Sistemas Transgressivo; TSNA: Trato de Sistemas de Nível Alto; TSRF: Trato de Sistemas de Regressão Forçada LS: Limite de Sequência.

Figura 16. Modelo estratigráfico evolutivo idealizado para o Trato de Sistemas de Nível Baixo da Sequência 3. 
comparados com os depositados no TSNB. Durante a deposição desse trato de sistemas, o sistema lacustre parece se expandir e avançar sobre áreas anteriormente ocupadas por desertos (Fig. 15).

O TSNA da SEQ2 é constituído basicamente por rochas siliciclásticas e raramente carbonáticas. A associaçáo litofaciológica desse trato de sistemas sugere que a sedimentaçáo ocorreu em um sistema lacustre, sob forte influência de sedimentos eólicos e de rios efêmeros em um ambiente desértico.

O contexto climático no qual a Bacia do Parnaíba estava inserida durante o Triássico está bem representado pelos arenitos do TSNB da SEQ3. Esse trato de sistemas encerra a deposição sedimentar com uma fase regressiva, que culminou com o término da sedimentaçáo de origem marinha/costeira e lacustre na bacia e a instalação de um grande deserto, materializado pelos arenitos da Formaçáo Sambaíba (Fig. 16).

\section{CONCLUSÕES}

A aplicação da estratigrafia de sequências ao estudo da Sequência Neocarbonífera-Eotriássica da Bacia do Parnaíba, com base na análise de dados de poços e linhas sísmicas, tornou possível reconhecer três sequências deposicionais de mais alta frequência separadas por discordâncias que revelam importantes episódios de reduçáo do espaço de acomodação ocorridos durante a deposiçấo da sequência estudada.

O reconhecimento de mudanças sistemáticas das litofácies nos poços estudados tornou possível inferir a evoluçáo dos diferentes contextos deposicionais, que foi bem retratada pelas variaçóes climáticas e ambientais às quais a bacia esteve submetida naquela época.

A Sequência Neocarbonífera-Eotriássica inicia-se com depósitos fluviais e eólicos associados que são afogados por depósitos marinhos e costeiros em condiçôes de clima árido a semiárido, como consequência de um pulso inicial transgressivo. A partir daí, já em uma tendência regressiva, os depósitos marinhos são progressivamente substituídos por sistemas lacustres e desérticos, culminando em um amplo ambiente de dunas eólicas, fruto de um pulso regressivo.

O comportamento lateral das unidades genéticas estudadas, quando analisadas nas seçóes sísmicas e na seção de correlação, revela que elas apresentam espessura, na maioria das vezes, aproximada, fato característico do contexto de sinéclise intracratônica em que tais sequências foram depositadas.

\section{AGRADECIMENTOS}

Os autores agradecem ao Programa de Pós-Graduaçáo em Geologia e Geofísica (PPGG), ao Departamento de Geologia (DG) e ao Laboratório de Geologia e Geofísica do Petróleo (LGGP) da UFRN. Os autores também são gratos ao Projeto de Pesquisa "Geologia e Sistemas Petrolíferos da Bacia Intracratônica do Parnaíba, Nordeste do Brasil” (BPAR), pela concessão dos dados utilizados nesta pesquisa, e à Agência Nacional do Petróleo (ANP), pela concessão da bolsa de mestrado do primeiro autor.

\section{REFERENCES}

Abrantes Júnior F.R. 2013. A zona de contato entre as formações Motuca e Sambaíba, Permo-Triássico da Bacia do Parnaíba, região de Filadélfia (TO), Riachão (MA) e Loreto (MA). MS Dissertation, Universidade Federal do Pará, Belém, 81 p.

Abrantes Júnior, F.R. \& Nogueira, A.C.R. 2013. Reconstituição paleoambiental das formações Motuca e Sambaíba, Permo-Triássico da Bacia do Parnaíba no sudoeste do Estado do Maranhão, Brasil. Revista do Instituto de Geociências - USP, 13(3):65-82.

Andrade L.S. 2012. Fácies e estratigrafia da parte superior da Formação Pedra de Fogo, Permiano da Bacia do Parnaiba, Região de Filadélfia - TO. MS Dissertation, Universidade Federal do Pará, Belém, 87 p.

Araújo R.N. 2015. Depósitos lacustres rasos da Formação Pedra de Fogo, Permiano da Bacia do Parnaiba, Brasil. MS Dissertation, Universidade Federal do Pará, Belém, 50 p.

Catuneanu O. 2006. Principles of sequence stratigraphy. Edmonton, Elsevier Science. 375 p.

Dino R., Antonioli L., Braz S.M.Z. 2002. Palynological data from the Trisidela Member of Upper Pedra de Fogo Formation (“Upper Permian") of the Parnaíba Basin, Northeast Brazil. Revista Brasileira de Paleontologia, 3:24-35.
Embry A.F. \& Johannessen E.P. 1992. T-R sequence stratigraphy, facies analysis and reservoir distribuition in the uppermost Triassic-Lower Jurassic succession, western Sverdrup Basin, Artic Canada. In: Vorren T.O., Bergsager E., Dahl-Stamnes O.A., Holter E., Johansen B., Lie E., Lund T.B. (eds.) Arctic Geology and Petroleum Potential. Norwegian Petroleum Society, Special Publication 2. Amsterdam, Elsevier, p. 121-146.

Faria Junior. L.E.C. 1979. Estudo sedimentológico da Formação Pedra de Fogo - Permiano- Bacia do Maranhão. MS Dissertation, Núcleo de Ciências Geofísicas e Geológicas, Universidade Federal do Pará, Belém, $57 \mathrm{p}$

Galloway W.E. 1989. Genetic stratigraphic sequences in basin analysis. In: Architecture and genesis of flooding-surface bounded depositional units. American Association of Petroleum Geologists Bulletin, 71:125-142.

Góes A.M.O. \& Feijó F.J. 1994. Bacia do Parnaíba. Rio de Janeiro, Boletim de Geociências da Petrobrás, 8(1):57-68.

Holz M. 2012. Estratigrafia de Sequências: histórico, princípios e aplicações. Rio de Janeiro, Interciência, 272 p.

Hunt D. \& Tucker M.E. 1992. Stranded parasequenes and the forced regressive wedge system tract: deposition during base-level fall. Sedimentary Geology, 81:1-9. 
Lima E.A.M. \& Leite J.F. 1978. Projeto estudo global dos recursos mineiras da Bacia Sedimentar do Parnaíba: integração geológicametalogenética. Recife, Companhia de Pesquisa de Recursos Minerais, Relatório Final da Etapa III, 212 p.

Medeiros R.S.P. 2013. Reconstituição paleoambiental da Formação Pedra de Fogo na borda da Bacia do Parnaíba, na região de Araguaiana (TO). Relatório de Conclusão de Curso, Universidade Federal do Pará, Belém, 105 p.

Melo M.T. \& Prade G.O. 1968. Geologia da Região Sudeste de São Raimundo das Mangabeiras - Maranhão. Belém, Petrobrás. Relatório 29M, 37 p.

Milani E.J. \& Thomaz Filho A. 2000. Sedimentary Basins of South America. In: Cordani U.G., Milani E.J., Thomaz Filho A., Campos D.A. (eds.) Tectonic Evolution of South America. Rio de Janeiro: $31^{\circ}$ International Geological Congress, p. 389-452.

Oliveira M.A. 1982. O padrão de distribuição dos elementos traços na formação Pedra de Fogo, Permiano da Bacia do Maranhão e seu emprego como indicador de ambientes de sedimentação. MS Dissertation, Universidade Federal do Pará, Belém, $94 \mathrm{p}$
Ribeiro C.M.M. 2000. Análise faciológica das Formações Poti e Piauí (Carbonífero da Bacia do Parnaíba) na Regia de Floriano-PI. MS Dissertation, Universidade Federal do Pará, Belém, 96 p.

Santos M.E.C.M. \& Carvalho M.S.S. 2004. Paleontologia das bacias do Parnaíba, Grajaú e São Luís. Programa de Levantamentos Geológicos Básicos do Brasil. CPRM, Serviço Geológico do Brasil/DIEDIG/DEPAT, Rio de Janeiro, 211 p.

Van Wagoner J.C., Posamentier H.W., Mitchum R.M., Vail P.R., Sarg J.F., Loutit T.S., Hardenbol J. 1988. An overview of sequence estratigraphy and key definitions. In: Wilgus C.K., Hastings B.S., Kendal C.G.St.C., Posamentier H.W. Ross C.A., Van Wagoner J.C. (eds.) Sea level changes - an integrated approach. Tulsa, SEPM Special Publication, p. 39-45.

Vaz P.T., Rezende V.G.A.M., Wanderley Filho J.R., Travassos W.A.S. 2007. Bacia do Parnaíba. Rio de Janeiro, Boletim de Geociências da Petrobrás, 15(2):253-263.

Wright, V.P. \& Marriott, S.B. 1993. The sequence stratigraphy of fluvial depositional systems: the role of floodplain sediment storage. Sedimentary Geology, 86:203-210.

Arquivo digital disponível on-line no site www.sbgeo.org.br 